\title{
Presentación:
}

\section{Educación para la Diversidad Sexual y de Género}

\author{
Education for Sexual and Gender Diversity
}

\author{
Soledad Cid * \\ Universidad Central de Chile
}

La educación inclusiva es un proceso en pleno desarrollo en muchos países. Un camino que conlleva grandes tensiones, temores y contradicciones, las que en particular parecen profundizarse cuando la inclusión se refiere a la diversidad de género y sexual. Estos temores y tensiones suelen encontrar sus puntos de sustento en las comprensiones que portan los diversos actores del mundo socio cultural con respecto a lo que es el sujeto y lo que es adecuado y deseable a su ser.

En los últimos años, ha ido ganando terreno tanto en el ámbito público como en los círculos del mundo educativo, la discusión sobre el impacto de los procesos formativos en la construcción y afirmación de la identidad de género y sexual y, en consecuencia, acerca del papel que le compete a la institución escolar en la promoción y desarrollo de una convivencia basada en el reconocimiento y valoración entre quienes transitan diversos caminos de construcción de identidad de género y sexual. Sin embargo, esto no significa que la construcción de identidades de género y sexual no hegemónicas se encuentren en camino de una aceptación en el marco de lo que se considera como "normal" en nuestro mundo cultural. Tampoco significa que en el contexto educativo la convivencia entre personas con diversas identidades, desde la perspectiva del género o sexo, sea simple o sin contradicciones, ni fácil de abordar por las comunidades educativas.

Por el contrario, lo que en la realidad se suele observar es la existencia de un discurso "oficial" que aboga por el reconocimiento y aceptación de la diversidad sexual en la vida escolar. Sin embargo, con frecuencia este discurso oficial subsume otro discurso más complejo y tensionado en el que gravitan imaginarios que se relacionan con lo que se considera adecuado y deseable. Discurso en el que tienden a aparecer referencias relativas a lo que "los otros", externos a los muros del centro educativo, pueden hacer o decir si el centro asume un tránsito que cuestione los deslindes de lo socialmente adecuado. En estos discursos, esos "otros" pueden provenir de la comunidad local como también de las administraciones educativas, los que emergen como posibles sancionadores, de formas más o menos simbólicas o concretas según las distintas construcciones discursivas con respecto a una comunidad educativa que rompa con el silencio, la ocultación o la invisibilización de experiencias identitarias de género o sexual no hegemónicas.

En especial, lo anterior se pone en evidencia en aquellas instituciones educativas en las que integrantes de la comunidad educativa (estudiantes, docentes, personal administrativo...) han explicitado su identidad sexual no hegemónica y exigido su derecho

*Contacto: solcidr@gmail.com

ISSN: 0718-7378

www.rinace.net/rlei/ 
a ser reconocidos y validados por su comunidad. Si bien hay espacios educativos que han asumido esa presencia-exigencia como algo adecuado e incluso deseable, estas prácticas están lejos de ser habituales. Lo que más bien emerge, en especial cuando la discusión sobre el tema se abre a todos y todas, son situaciones de tensión, desencuentros y temores entre los miembros de la comunidad educativa. Estas tensiones surgen, a mi entender, porque desde el imaginario colectivo experiencias como la señalada implican una posibilidad real de conflicto, ya sea con las familias, con los estudiantes, los docentes, la comunidad local, pero por sobre todo con las propias visiones y expectativas de adecuación que poseen quienes forman parte de ese centro educativo en particular. Desde una mirada antropológica, mi campo disciplinario de origen, no se trata de tensiones o contradicciones anecdóticas o antojadizas, si no de la expresión de conflictos no resueltos que nos transitan a todos y todas como integrantes del mundo cultural que cotidianamente habitamosconstruimos, incluso a quienes vivimos desde las identidades no hegemónicas.

De allí que la edición de un número de la Revista Latinoamericana de Educación Inclusiva dedicado al tema de la educación en y para la diversidad sexual y de género constituya un aporte relevante al debate técnico en dicho campo, pero sobre todo un avance para la apertura al espacio simbólico educacional, el que aún no ha sido colonizado por las sensaciones de seguridad y aceptación sin restricciones a las diversidades identitarias no hegemónicas en sexualidad y género, que si están presentes en otros espacios culturales de Latinoamérica.

Desde esta perspectiva el presente número debe ser entendido en primer lugar, como una posibilidad de poner en tensión las concepciones dicotómicas de corrección e inadecuación en el plano de la identidad de sexo y género y, en segundo lugar, una ventana a la incursión de lo que está ocurriendo en el contexto educativo con respecto a la relación cotidiana entre lo real y lo imaginado en dichos planos identitarios y las construcciones de vivencias formativas desde la cotidianeidad escolar.

De esta tensión nos habla Pablo Astudillo en su investigación respecto al reconocimiento del mundo de la diversidad sexual en procesos formativos de escuelas vinculadas a un credo religioso, y de las tensiones que en dicho reconocimiento se redefinen. De la lucha por empujar esos deslindes nos iluminan Sylvia Contreras y Mónica Ramírez y, en relación a las formas de transitar y resistir frente a la dicotomización correcto/incorrecto que se observan en los contextos educativos. Estas autoras nos hablan de las estrategias generadas por parte de quienes son parte de las diversidades sexuales en el nivel de educación secundaria, y el develamiento de éste como un escenario con mayores condiciones de acción contra hegemónica que el de la educación primaria. Nos relatan como la existencia de este espacio simbólico, en el que la presencia de la diversidad se ofrece a la vista de los estudiantes, no implica que dichas identidades pierdan el sello de discriminadas, llevándonos a reflexionar sobre los deslindes y claro obscuros que dicha oportunidad significa en el contexto de pensar en un mundo socio cultural inclusivo.

El artículo de Cristina Julio, Anna Kaeuffer, Christopher Riquelme, María Paz Silva, María Roswitha Osorio y Natalie Torres, nos permite reflexionar, desde una perspectiva comprensiva, acerca del manejo que poseen los docentes que ejercen en el nivel de educación inicial y del primer ciclo de básica sobre el tema de la diversidad sexual. Nos ofrece una ventana para entender la forma en que dichas comprensiones constituyen a los docentes en facilitadores u obstáculos para el desarrollo de experiencias de inclusión. La mirada que ofrece este artículo con respecto a la influencia de la política pública y, 
específicamente educativa, resulta una triangulación de interés al momento de pensar en las condiciones favorecedoras para la construcción de identidades diversas, así como para reflexionar la experiencia escolar como favorecedora de aprendizajes de vivencia en diversidad. La detección, a partir de los relatos de los docentes, de una importante presencia de comprensiones de tipo esencialista en relación a la construcción de la identidad sexual es un tema no menor, el que se debe tener en el horizonte al momento de construir caminos para una educación inclusiva.

Respecto a los aconteceres en el aula en el marco de la implementación de experiencias educativas que propenden a la concreción de prácticas educativas inclusivas en sexualidad y género, nos hablan los trabajos de Natalia y Margarita Salas y de Caterine Galaz, Lelya Troncoso y Rodolfo Morrison, respectivamente, permitiéndonos reflexionar tanto sobre la potencia del quehacer docente como motor de transformación, también en relación a los nudos críticos que se requiere aun deconstruir para avanzar en estos procesos.

Por su parte, la sección temática de este número incluye cinco interesantes artículos. Los dos primeros trabajos aportan a la reflexión con relación a los nudos críticos que resultan transversales en nuestros países latinoamericanos en el marco de las percepciones con respecto a la educación inclusiva de dos actores fundamentales de las comunidades educativas: los padres y los docentes. En el caso del primer artículo, Paola Ruiz nos convida a reflexionar respecto a los actores participantes en espacios educativos peruanos. Las comprensiones develadas, vinculan la inclusión a personas con necesidades educativas especiales, emergiendo un tema de gran relevancia, la falta de sensibilidad en relación a los fenómenos de exclusión y sus efectos en los sujetos que la sufren.

El segundo trabajo de Sergio Sánchez, Lilian Castro, José Antonio Casas y Vivian Vallejos consistente en un estudio con acercamiento cuantitativo, nos habla de las percepciones de futuros docentes chilenos con relación a las orientaciones del Diseño Universal para el Aprendizaje con énfasis integrador. En este artículo se plantea una apreciación positiva sobre elementos relacionados con en el primer y tercer principio de dicho modelo. A partir de lo anterior un tema de importancia es como se transita en los procesos formativos de futuros docentes, de manera tal que se potencien sus capacidades para desarrollar experiencias formativas inclusivas.

Los trabajos de Marta Terrén y Auxiliadora Sales y el de Miroslava Cruz-Aldrete y Miguel Ángel Villa nos muestra la importancia de experiencias formativas concretas en el espacio de la educación inclusiva, las que nos mueven a la reflexión respecto a los modelos formativos y las estrategias educativas para el logro efectivo de la inclusión, sus retos y sus potencialidades.

Finalmente el artículo de Gabriela Bard y Gabriela Artazo nos permite comprender las formas en que se mantienen los deslindes nosotros-otros en espacios formativos que han alcanzado prestigio académico, lo que indica que siempre es posible afinar la mirada con respecto al tema de la calidad y las dimensiones que pueden ser incluidas o de serlo al analizar este tema en la educación terciaria.

De esta forma, la interesante selección de artículos que incluye esta edición, nos aporta una mirada al tema de los caminos posibles, sus intersticios y los retos que aún nos quedan por delante, a quienes no solo nos importa el tema de la inclusión en educación, sino a todos aquellos que creemos que la inclusión es una de las puertas para generar experiencias que nos lleven a caminar por el sendero que Freire nos ofrecía: la educación 
como experiencia de construcción de sujetos autónomos y potentes, actores centrales de la construcción de una cultura que nos permita reconocernos en y con los otros.

\section{Breve CV de la autora}

\section{Soledad Cid}

Es Antropologa Social y Licenciada en Antroplología de la Universidad de Chile, Magíster en Ciencias Sociales, mención en Política Pública en la Universidad Arcis. Se ha especializado en Cultura Escolar, siendo en este campo su principal interés los procesos de conformación identitaria docente, participando en investigaciones referentes a los efectos de las estrategias de evaluación estandarizadas en dicha construcción. Trabaja actualmente apoyando comunidades educativas en procesos de trabajo en diversidad sexual y de género e inclusión educativa, participando, simultáneamente, como relatora invitada para comunidades educativas en diversas experiencias respecto al trabajo inclusivo. Forma parte de la Comisión de Educación de una de las organizaciones de diversidad sexual en Chile y ha participado como analista de procesos de formación en post grado, siendo actualmente docente de postgrado. Actualmente se encuentra realizando su trabajo de doctorado en la temática de la racionalidad docente frente al tema de inclusión. Email: solcidr@gmail.com 